\title{
As Teorias Psicossociais do Desenvolvimento Econômico: Comentários Críticos \\ José Pastore*
}

1. Introdução. 2. A Teoria de Mc-Clelland. 3. A Teoria de Hagen. 4. Sumário e Conclusões.

\section{Introdução}

O desenvolvimento econômico estudado durante muito tempo dentro de um sistema fechado, no qual as variáveis mais relevantes eram capital, trabalho, matérias-primas e energia. Só recentemente alguns economistas perceberam a importância de variáveis subjacentes ao desenvolvimento econômico e que escapam àquele sistema. Começou-se então a desenvolver uma perspectiva mais inclusiva. De início, esta perspectiva baseou-se nos pressupostos de uma psicologia predominantemente racional, também chamada de psicologia econômica: esta postura enfatizava o papel à criatividade humana para produzir as inovações tecnológicas, responsáveis pelos aumentos da produtividade. Mais recentemente, entretanto, economistas e também sociólogos vêm enfatizando os fatôres não-racionais e não-econômicos do comportamento econômico; tentam mostrar que motivos irracionais, mudanças no gôsto e aceitação de riscos são elementos importantes para explicar o desenvolvimento econômico. Parecem concordar, enfim, que desenvolvimento econômico só pode ser explicado em têrmos de um sistema complexo de variáveis econômicas, sociais e políticas. Surgiu assim uma

* Professor-Assistente da Faculdade de Filosofia, Ciências e Letras e Pesquisador do Instituto de Pesquisas Econômicas da Universidade de São Paulo.

'R. Adm. Emp., Rio de Janeiro, $10(1): 79 / 94, \quad$ jan./mar. 1970 
perspectiva de trabalho interdisciplinar entre economistas, sociólogos e outros cientistas sociais.

David C. McClelland e Everett E. Hagen são dois representantes dessa perspectiva. A análise do primeiro, concentrando-se nos elementos psicológicos, procura identificar as variáveis que produzem personalidades empresariais. Os ensaios de HAGEN, mais compreensivos, tendem demonstrar os laços entre personalidade, sociedade e desenvolvimento econômico.

O objetivo dêste artigo é avaliar até que ponto os dois autores preencheram o vazio existente nas teorias econômicas do desenvolvimento econômico. Mais modestamente, êste trabalho procura comparar as duas teorias e tenta julgar a validade lógica e empírica incorporadas nas análises de MCClelland e HAGEN. A escolha dessas duas teorias foi baseada em parte na originalidade das mesmas e, em grande parte, na popularidade que elas vêm desfrutando nos círculos acadêmicos nos últimos anos.

\section{A teoria de McClelland 1}

\subsection{ANÁLISE DOS TÊRMOS BÁSICOS}

O objetivo básico da teoria de McClelland é explicar a importância dos fatôres e processos psicológicos no desenvolvimento econômico. Ele está interessado em estudar os valôres e motivações que levam os homens a explorar as oportunidades e a tirar vantagens das condições favoráveis de comércio. Enquanto psicólogo social, McClelland deseja compreender as motivações dos empresários bem sucedidos.

\section{a) Motivação para Realização}

A primeira entre estas motivações é a necessidade de realização ( $\mathrm{n}$ - achievement). Ela exprime o desejo de fazer bem feito, não tanto com vistas ao reconhecimento ou prestígio social, mas principalmente para obter um sentimento íntimo de realização pessoal. Estudos de laboratório já haviam mostrado que as pessoas com alto grau de n-achievement tendiam a trabalhar mais intensamente em

1 MoClelland, David C. The Achieving Society, Nova Iorque, D. van Nestrand Co., Inc., 1961. 
certas tarefas, a realizar seu melhor trabalho com interêsse pessoal e não simplesmente motivadas por incentivos especiais, como dinheiro ou prêmios; essas pessoas tendiam a escolher especialistas como calegas de trabalho. Dêsses resultados, McClelland concluiu pela existência de uma alta relação entre o nível de motivaçâo para realização de um determinado povo e o nível de desenvolvimento econômico de seu país (p. 55 a 57)..$^{2}$

O elo entre os dois fenômenos sociais seria constituído pelos empresários. Portanto, conclui êle, a motivação de realização dos empresários é responsável, em parte, pelo crescimento econômico (p. 159).

\section{b) Educação da Criança}

Para MCClelland é na família que se deve procurar os determinantes intrínsecos da motivação para realização. Mais especificamente, sugere que as práticas educacionais baseadas na independência, no domínio de si e na liberdade, fornecem melhores condições para a formação daquela motivação (p. 341 e 342 ).

A evidência empírica para estas afirmações é fornecida pelo estudo de WinterbotTom citado por MCClelland e que pôde ser sumariado da seguinte maneira: "as mães das crianças com alto nível de motivação para realização têm tendência a esperar da criança maior contrôle de autoconfiança do que as mães de crianças de baixo nível de motivação. Elas fazem também menos restrições a seus filhos... as mães de crianças com baixo nível de motivação, ao contrário, fazem mais restrições e não esperam que seus filhos manifestem, tão cedo, independência e domínio de si. Numa palavra, seus filhos são mais dependentes em relação aos adultos" (p. 342 e 46).

Embora estudos posteriores tivessem mostrado que os resultados de WINTERBOTTOM não se mantinham com a mesma clareza quando se introduzia outras variáveis, MCCLELLAND ainda assim considera que o treino no domínio de si nos primeiros estágios da infância possibilita um alto nível de motivação para realização. Com efeito, êste é um de seus argumentos básicos que parece, aliás, falacioso em dois pontos: a) o próprio MCClelland reconhece que, ao serem introduzidas outras variáveis (por exemplo, classe social, côr, etnia etc.), os resul-

2 As páginas referem-se à edição citada (1961). 
tados não são tão claros quanto antes; b) o estudo de WINTERBotToM baseava-se numa amostra muito pequena: 29 garotos de 8 anos (p. 46), o que não parece ser representativo de um amplo universo.

\section{c) Autoritarismo}

ROSEN e D'ANDRADE não ficaram satisfeitos com as informações dadas pelas mães sôbre a educação das crianças e tentaram observar as interações pais-filhos em 40 famílias ( 20 de alto nível e 20 de baixo nível de n-realização). O experimento, citado por McCelelland, foi delineado com maior cuidado e incluía garotos entre 9 e 11 anos que foram, além disso, emparelhados segundo a classe social, raça e inteligência (p. 350). Descobriram que os pais dos garotos de alto nível de motivação revelavam menos comportamento dominante do que os pais de baixo nível (p. 352).

Duas críticas devem ser ainda levantadas: a) os autores só estudaram uma interação particular, isto é, as relações pais-filhos numa situação de jôgo (o jôgo de empilhar cubos). Isso não fornece nenhuma evidência que esta relação particular represente uma projeção geral de suas atitudes em outras tarefas. b) a definição de autoritarismo em têrmos de estimular ou dominar a criança durante o jôgo não parece, igualmente, muito clara.

\section{d) Religião}

Seguindo as idéias de Weber e de Winterbottom, McClelland sugere umá relação positiva entre protestantismo, domínio de si e independência na educação da criança e, portanto, entre protestantismo e alto nível de motivação para realização. Ele parte de uma comparação entre níveis de desenvolvimento econômico em regiões católicas e protestantes (p. 50 a 54).

Neste contexto a religião é estudada como uma fonte de valôres paternos e supõe-se que tais valôres afetam as práticas de educação infantil e, portanto, o nível de motivação para realizaçã́o (p. 356). Estudos efetuados nos Estados Unidos, entretanto, mostram que as diferenças acima indicadas pràticamente desaparecem quando controladas por classe social (p. 356 a 362). Em segundo lugar, os estudos sôbre a religião limitaram-se à análise das doutrinas professadas 
pelos pais e não a seus valôres e atitudes. Inferir da doutrina as atitudes e os comportamentos dos indivíduos não parece correto, em têrmos gerais.

\section{e) O Empresário}

Examinamos, nas três últimas seções, as fontes de motivação para realização. Nesta seção trataremos da relação entre empresário e desenvolvimento econômico. McClellaNd afirma: "uma sociedade com um nível geralmente alto de motivação para realização irá produzir empresários mais empreendedores, os quais, por sua vez, provocarão maior desenvolvimento econômico" (p. 205).

A estratégia metodológica que MCCLELlaNd usa neste ponto parece inadequada por várias razões: a) êle descreve, primeiro, os empresários e, então, mostra que êles possuem as mesmas características encontradas entre os grandes realizadores. Estes, por sua vez, são aquêles indivíduos que têm altas aspirações pelas ocupações empresariais (p. 210 a 233). Este procedimento, entretanto, não parece um modo direto de trazer evidência para sua hipótese. Variação concomitante não significa causação, mas, simplesmente, um primeiro passo, muito elementar, aliás, de trabalho teórico. Pode-se dizer que McClelland alcança apenas uma generalização empírica e não uma explicação teórica. b) quanto à segunda parte da hipótese de MCCLELLAND os empresários provocarão o desenvolvimento econômico - pode-se fazer outra crítica. Nota-se que McClelland insiste no uso da palavra provocar em suas proposições. Esta palavra faz parte do vocabulário da linguagem causal. Com efeito, quando dizemos que $\mathrm{X}$ é causa de $Y$, temos em mente que uma mudança em $X$ produz necessàriamente uma mudança em $Y$. $O$ emprêgo da linguagem causal é muito discutível não só em Sociologia mas também em outras ciências. ${ }^{3}$ Entretanto, desde que MCCLELLAND insiste nela, êle deveria fornecer evidência direta da qualidade produtora da motivação para realização e do empresariado no desenvolvimento econômico. Mas isto não está nada claro em seu trabalho. c) McClelland parece supor que as pessoas com alto nível de motivação para realização se orientam, necessàriamente, para o setor dos negócios. Ele não menciona, entre-

3 Ver Pastore, José. Problemas Metodológicos na Construção de Teorias sôbre Desenvolvimento Econômico, RAE, n. ${ }^{\circ}$ 27, 1967. 
tanto, a razão desta exclusividade. Com efeito, poderíamos conceber a motivação para realização em têrmos de valôres culturais mais amplos; os grandes realizadores podem dirigir-se às artes, à vida monástica, etc., onde os padrões de excelência não se definem em têrmos de uma orientação aos valôres do negócio. Numa sociedade budista, por exemplo, que valoriza o afastamento da vida econômica mundana e a obtenção do Nirvana, os maiores realizadores não orientariam suas realizações na direção do Nirvana em vez da atividade econômica? d) Ainda que as provas de MCClelland, da fôrça produtora do empresariado no desenvolvimento econômico, fôssem válidas, resta ainda um outro problema a considerar. Em sua proposição, MCClellaNd parece supor uma distribuição perfeita da produção entre as diferentes classes sociais. Esta premissa pode revelar-se falsa em muitas sociedades. Há sociedades onde o aumento de produtividade dos empresários é consumido, principalmente, entre êles mesmos.

\subsection{METODOLOGIA}

O principal indicador de desenvolvimento econômico, na teoria de MCClelland, é o consumo (per capita) de eletricidade. Embora êle apresente certas justificações racionais para isto (p. 50 e 51), deve-se dizer que o caráter transcultural que êle quer dar à sua teoria parece ficar muito reduzido, pois que muitas sociedades subdesenvolvidas estão atravessando o estágio do take-off através de implementações maciças da agricultura e da produção de matérias-primas que não exigem, a curto têrmo, grande quantidade de eletricidade.

De outro lado, o emprêgo de estórias infantis para medir o nível de motivação para realização de um país como um todo não parece dispor de forte apoio. McClelland afirma, a certa altura, que as estórias infantis são espelhos fiéis de uma sociedade (p. 71), e, em outro trecho, "as estórias parecem refletir melhor o nível motivacional dos adultos... particularmente dos adultos responsáveis pela educação das crianças..." (p. 102). Existem três problemas, pelo menos, em inferir que quanto mais alto o nível de motivação para realização refletido nestas estórias, maior o desenvolvimento econômico: a) MCClellaNd não mostra que as estórias infantis refletem o nível de motivação para realização dos empresários. Dêste modo, seu fator de uniăo entre a motivação e o desenvolvimento econômico está inutilizado e, portanto, a inferência lógica não parece exata. b) Muitos 
estudos mostraram que o artista, em geral, e o escritor, em particular, realizam normalmente seu trabalho criativo não só como resposta a um público amplo, mas, sobretudo, como resposta a seus próprios grupos de referência. Desta maneira, poderíamos levantar a hipótese de que as estórias infantis não representam necessàriamente o ethos da sociedade na qual elas têm sua origem. c) Finalmente, é preciso lembrar ainda que os diferentes índices de motivação para realização usados por MCCLELLAND (verbal e gráficos) não se correlacionam muito bem entre si (p. 77). Isto parece revelar algumas das fraquezas dos indicadores e técnicas de identificação dos níveis de motivação.

\subsection{ESTRUTURA LÓGICA DA TEORIA}

\section{a) Definições}

MCClelland revela uma preocupação bastante louvável em definir seus conceitos. Além disso, êle mostra, muitas vêzes, como operacioná-los:

- Motivação para realização é o desejo de fazer bem feito, não tanto em vista de reconhecimento social, mas a fim de atingir um sentimento íntimo de realização pessoal. E a necessidade que tem um indivíduo de definir padrões de excelência (p. 47 e 48 ).

- Empresário é o indivíduo que exerce contrôle sôbre a produção a qual não se destina sòmente a seu consumo pessoal.

- Desenvolvimento econômico é o aumento na taxa per capita dos serviços de produção, e o emprêgo de inovações tecnológicas (p. 85).

Algumas das definições de McClelland, entretanto, baseiam-se demais em elementos operacionais. O conceito de desenvolvimento econômico, por exemplo, pode não ser completamente claro se a "energia elétrica não fôr considerada como principal indicador. Conceitos auxiliares, como independência na educação da criança, autoritarismo, são definidos sòmente com base operacional" (p. 352).

\section{b) Comentários Gerais Sôbre a Lógica}

De modo geral, a motivação para realização é compreendida como uma condição necessária de desenvolvimento econômico: “... a mo- 
tivação de realização é, em parte, responsável, pelo desenvolvimento econômico" (p. 36) : “...é improvável que... o crescimento econômico seria o resultado de um único propulsor" (p. 159). Em outras passagens, ent:etanto, MCClelland parece ir mais longe e indicar um caráter suficiente nesta relação: “. . .quando uma alta associação entre motivação para reaılzação e sucesso empresarial não é obtida, pode-se considerar, prima facie, que uma ou mais condições definidoras do papel empresarial, no sentido teórico, não foram preenchidas" (p. 271).

Entretanto, os dados fornecidos pelo estudo de casos históricos (Estados Unidos, México, Itália, Turquia, India e Polônia), apresentados no capítulo 7, não provam, de modo convincente, nem o caráter necessário nem o caráter suficiente do nível da motivação para rẹalização do crescimento econômico (ver sobretudo tabelas 3,4 e 3.6 , p. 90 a 100).

Os comentários acima deixam claro que não há consistência lógica na inferência de motivação para realização dos empresários a partir das estórias infantis. De outro lado, a dimensão tempo na proposição básica de MCClellaNd não está cuidadosamente formulada. Isto torna extremamente difícil atribuir causalidade a qualquer das cláusulas antecedentes. O problema do que acontece primeiro é muito pertinente no caso, mas o delineamento lógico de MCCLELLAND não oferece resposta satisfatória. Além disso, as proposições não parecem irreversíveis entre as cláusulas antecedente e consequiente; isto cria um problema extra de atribuição de causalidade. Numa palavra, a reversibilidade constante da proposição enfraquece a fôrça causal da explicação de MCClelLAND.

\section{A teoria de Hagent}

\subsection{ANÁLISE DOS TÊRMOS BÁSICOS DA TEORIA}

O principal objetivo da teoria de HAGEN é igualmente traçar uma linha de causalidade entre os fatôres sociopsicológicos e desenvolvimento econômico. Enquanto MCClelland considera a motivação para a realização, HAGEN considera a personalidade inovadora como

4 Hagen, Everett E. On the Theory of Social Change, Itomewood, The Dorsey Press, Inc., 1962. 
conceito chave de sua cadeia de proposições. Até certo ponto, a teoria de HAGEN parece mais compreensiva do que a de McClelland. Ele tenta relacionar sociedade, personalidade e desenvolvimento econômico.

\section{a) Personalidade Inovadora}

HAGEN, à semelhança de muitos outros economistas, assume que as inovações tecnológicas são condições básicas necessárias para o desenvolvimento econômico. Mas, ao contrário de outros economistas, êle se preocupa com as cláusulas antecedentes da inovação. Para êle, inovação requer criatividade e, portanto, personalidade inovadora que é a personalidade criadora. "O progresso tecnológico é o resultado das ações de homens que se caracterizam por vários graus de criatividade" (p. 88); “.... as intercorrelações entre personalidade e estrutura social são de tal natureza a não deixar dúvidas de que a mudança social não ocorrerá sem mudanças nas personalidades" (p. 86).

Um dos principais problemas na teoria de HAGEN se refere às definições. Por exemplo seus conceitos chaves - criatividade e personalidade inovadora - não são claramente definidos. HAGEN geralmente apresenta características da criatividade e da personalidade inovadora mas não definições claras. Este aspecto será discutido extensamente nas próximas seções.

\section{b) Criatividade}

Mesmo oferecendo uma definição clara de inovação - "a inovação consiste em organizar a realidade dentro de relações que incorporam novos conceitos mentais e estéticos" (p. 86) - HAGEN só apresenta uma lista de características da criatividade ou, como diz êle, "qualidades que constituem a criatividade": abertura à experiência, tendência a perceber fenômenos, imaginação criadora, inteligência, energia, prazer na solução de problemas, etc. (p. 88 a 94).

Esta ausência de definição acarreta muitos problemas: a) torna difícil compreender o sentido das proposições que envolvem o conceito de criatividade; b) não dá respostas a questões do tipo: quando alguém possui criatividade?, é suficiente, para ter criatividade, dispor de espírito imaginativo, de energia e inteligência? c) a noção profunda de 
criatividade não estando explicitada, encontramo-nos na impossibilidade de definir precisamente a personalidade inovadora, por estar êste conceito baseado no primeiro. HAGEN apresenta igualmente características da personalidade inovadora em vez de definições nominais ou operacionais (p. 96). Do mesmo modo, em vez de definir a personalidade autoritária (barreira para o desenvolvimento econômico) êle diz simplesmente que "a personalidade autoritária é a negação do indivíduo criador" (p. 97).

\section{c) Educação da Criança}

Como McClelland, Hagen tenta compreender as causas das diferenças de personalidade a partir das experiências infantis. Pais'e estrutura social autoritários, diz êle, são fatôres causadores de personalidades autoritárias (p. 143). Ele fundamenta seu argumento em trabalhos sociopsicológicos incluindo os de MCCLELLAND (p. 158). Ele vai mais longe ainda ao dizer que pais e estrutura social autoritários são mais encontradiços em sociedades tradicionais (p. 143 a 157). Embora sua dicotomia entre sociedade tradicional e sociedade moderna apresente muitos problemas operacionais, acreditamos que a descrição dêstes dois pólos seja uma das melhores passagens de seu trabalho.

Segundo HAGEN, a formação da personalidade é um processo diretamente relacionado com a aquisição de respostas para a satisfação de necessidades básicas como: necessidades manipulatórias, agressivas e passivas (p. 104 a 110). Essa classificação é apresentada como exaustiva (p. 111), e cada tipo de necessidade é subdividido em muitos outros. O tipo de personalidade seria determinado pela predominância de um ou mais tipos de necessidades. Assim, no caso da predominância da succorant-nurturant, "a personalidade inovadora vê a pessoa com quem entra em contacto como um indivíduo com necessidades, valôres e visão do mundo semelhantes aos seus" (p. 111); êsse indivíduo esforça-se por satisfazer as necessidades do outro e deseja ser compreendido e auxiliado na satisfação de suas próprias necessidades. Mas "o indivíduo autoritário vê o outro como simples objeto do qual êle pode retirar algo. Não há lugar para empatia, para percepção do outro como tendo seu próprio sistema de necessidades, valôres e visão do mundo..." (p. 111).

Embora essas características pareçam se ajustar à nossa concepção inspiracional do autoritarismo, elas deveriam ser mais claras; deve- 
riam igualmente ser operacionalizadas de modo a permitir pontos bem nítidos no contínuo dos tipos de personalidade. Neste particular sofremos de grandes necessidades de uma definição operacional que HAGEN não fornece. Ele mesmo parece reconhecer que sua "compreensão das necessidades não se apóia senão em especulações passageiras" (p. 159).

\section{d) Descrição da Sociedade Tradicional}

O modêlo de HAGEN tenta evitar a armadilha da circularidade entre autoritarismo e sociedades tradicionais. Como rompe êle êste círculo vicioso? Quais são os fatôres que levarão um grupo a distinguir-se dos outros e a abandonar o tradicionalismo?

A resposta a estas questões são pontos cruciais na teoria de HAGEN. Com efeito, estas questões são respondidas de vários modos através de seu livro: ". . . a causa básica de tal mudança é a percepção de certos membros de algum grupo social de que seus fins e valôres não são respeitados por outros grupos na sociedade, a qual êles respeitam e cuja estima valorizam" (p. 185). Em outras palavras, a não satisfação do status de um indivíduo seria um início causal de mudança; a quebra das relações sociais hierarquizadas é produzida, segundo HAGEN, por 4 mecanismos específicos: a) deslocamento pela fôrça; b) desintegração dos símbolos valorativos; c) inconsistência dos símbolos de status; d) não aceitação em uma nova sociedade (p. 187 a 190). Estes mecanishos são "causa do declínio no respeito pelo status de algum grupo em uma sociedade" (p. 190).

Embora esta explanação pareça muito atraente, é preciso dizer, entretanto, que êle não especifica claramente as conexões entre aquêles mecanismos e a emergência da personalidade inovadora. Diga-se de passagem que, neste ponto, nem mesmo material bibliográfico é encontrado (p. 187 a 192). Além disso êle não indica a origem dêstes mecanismos. Somos levados assim, a afirmar que sua tentativa de evitar a circularidade não obteve sucesso total.

\subsection{METODOLOGIA}

Tanto a personalidade inovadora quanto a autoritária são estudadas, no trabalho de HAGEN, através de testes TAT. Em um de seus casos chave (Colômbia), os testes só foram aplicados a 20 homens de negó- 
cio de Medellín "cuja carreira qualifica-os como inovadores efetivos..." (p. 368) . "O grupo de contraste é constituído de um grupo de líderes da comunidade de Popayan..." (p. 368). Nota-se que o grupo de Medellín é muito pequeno mas o tamanho da amostra de Popayan nem sequer é conhecido. Apesar disso, HageN conclui que o primeiro grupo era composto principalmente de personalidades inovadoras e o segundo de personalidades autoritárias (368 e 369).

A metodologia que êle emprega parece igualmente fraca por outras razões: a) apesar do pequeno tamanho (e desconhecido) das amostras, as conclusões são muito ousadas: "as diferenças entre os grupos eram gritantes" (p. 369): mas, nenhum teste estatístico é apresentado no texto. Mesmo assim êle afirma: "a incidência de personalidades criadoras é, provàvelmente, muito mais alta entre os Antioqueños do que alhures e isto é uma importante causa de seu maior sucesso empresarial" (p. 369) . b) a afirmação anterior, se fôsse testada, exigiria pelo menos, uma amostra casualizada de Antioqueños e outra de nãoAntioqueños. Entretanto, HAGEN tomou 20 homens de negócio para representar os Antioqueños e $X$ líderes da comunidade de Popayan para representar os não-Antioqueños (p. 368). Portanto, as generalizações não se apóiam em evidência empírica que aguiente testes rigorosos. O próprio HaGEN reconhece que os "Antioqueños selecionados eram os mais aptos a apresentar personalidades criadoras" (p. 369). c) finalmente, é preciso salientar que HaGEN, mais que McClelland, insiste sôbre causalidade. Adotando esta linguagem, suas afirmações deveriam obedecer aos requisitos dos modelos causais. Entretanto, HAGEN não trabalha com sistemas fechados e nem mesmo com variáveis assimétricas; além disso êle não fornece evidência suficiente da qualidade produtora de suas variáveis independentes (criatividade etc.).

\subsection{ESTRUTURA LÓGICA DA TEORIA}

\section{a) Definições}

- declínio no respeito pelo status é a negação da ordem hierárquica num dado sistema (p. 185 e 186).

- personalidade inovadora é a personalidade com qualidades de criatividade; pessoa inconscientemente alerta a novos fenômenos (p. 87 a 89 ). 
- criatividade: sem definição específica.

- crescimento econômico: é o progresso na tecnologia e um aumento da produção per capita (p. 10).

\section{b) Comentários Gerais sôbre a Lógica}

Parece que Hagen, como McClelland, pretende montar uma teoria transcultural. Em certos trechos, entretanto, HAGEN é tentado a restringir sua teoria às sociedades tradicionais. Mas, se isto fôsse feito, não há dúvida que êle estaria envolvido numa série de tautologias. E talvez, por isto, que êle conserva um nível de generalidade muito alto.

Alguns problemas da teoria de MCCLELLAND encontram-se no trabalho de HAGEN: a) também êle assume que o desenvolvimento tecnológico devido às inovações tem as mesmas repercussões na sociedade como um todo. Isto pode ser falso, em particular nas sociedades onde benefícios do progresso tecnológico são consumidos principalmente por um pequeno segmento da estrutura social. b) embora não esteja explícita, a ceteris paribus de HAGEN parece assumir uma ausência de contrôles estritos, os quais, em muitas sociedades, impedem o declínio no respeito pelo status. Este parece ser o caso do Brasil rural onde parece existir, em estado latente, uma falta de respeito pelo status; ela não se torna aberta, talvez, porque os contrôles são muito estritos tornando a mudança de atitude uma decisão muito arriscada para os camponeses. HAGEN deveria, pois, especificar em que condições se efetua o declínio no respeito pelo status. Isto talvez forçasse HAGEN a se limitar às sociedades onde os contrôles estruturais se tornam disfuncionais para certos grupos que, assim, têm oportunidade de operar mudanças.

Outro aspecto a ser analisado é o referente à dinâmica das sociedades tradicionais. HAGEN parece supor um estado de estabilidade nas sociedades tradicionais. Este ponto, entretanto, é obscuro. Certos trechos deixam transparecer sua adesão a esta posição: a) "não haverá mudança social sem mudança nas personalidades" (p. 86); b) "a mudança social depende da participação ativa de personalidades inovadoras" (p. 96) mas "nas sociedades tradicionais predominam as per- 
sonalidades autoritárias" (p. 369); c) "as personalidades autoritárias das sociedades tradicionais não são criadoras" (p. 96). Em outros trechos êle parece negar esta estabilidade: "o progresso tecnológico contínuo ganha sempre mais terreno mesmo nas sociedades tradicionais" (p. 58). O problema se coloca nestes têrmos: se, de fato, êle assume esta estabilidade, não há dúvida que êle está tratando com uma premissa falsa, pois a mudança é inerente a qualquer sociedaḍe. Se, entretanto, êle não a supõe, então sua teoria parece ter onipresente tanto o antecedente (personalidade inovadora) como o consequiente (mudança). Para evitar êste êrro êle deveria especificar o período de tempo e/ou o número de personalidades inovadoras necessário para a mudança; êle deveria trabalhar com tipos progressivos de afirmações.

Não fica inteiramente claro se os antecedentes são cláusulas necessárias ou suficientes. Em relação a certas proposições êle afirma claramente que a desintegração de símbolos valorativos, etc., são condições suficientes para o declínio no respeito pelo status (p. 190). "Se os elementos básicos da estrutura social e da cultura não oferecem esta satisfação/objetivos e motivações dos membros da sociedade, a sociedade muda" (p. 71). Mas, em outros casos, HAGEN apresenta uma extensa justificativa só indicando condições necessárias: "a transição do crescimento econômico ocorre, de modo geral, através de um período de tempo considerável; o contato com as sociedades tecnològicamente avançadas é uma condição necessária, mas o progresso não ocorre simplesmente em virtude dêste contato; o progresso tecnológico requer um alto grau de criatividade; as inovações não são sòmente mudanças técnico-econômicas mas também sociais. Uma teoria do crescimento econômico deve levar em conta êstes aspectos. Em si êles não são suficientes para a formulação de uma teoria... (p. $34 \mathrm{e}$ 35). Em outros trechos HageN torna-se realmente obscuro e suas cláusulas antecedente e consequiente nada mais parecem que simples tautologias: "se as condições econômicas mudam para melhor ao mesmo tempo que a personalidade torna-se mais favorável, então, òbviamente, o ímpeto de progresso é aumentado" (p. 240). Além do aspecto de circularidade desta afirmação, devemos acrescentar que a liberdade excessiva na linguagem (melhor, mais favorável, etc.) neutraliza o poder explicativo das proposições. 


\section{Seminário e conclusóes}

Sem dúvida alguma, pode-se considerar as teorias de Hagen e McClelland como uma tentativa bastante frutífera de mudar a visão clássica do desenvolvimento econômico baseadas em premissas que enfatizavam sobretudo a mudança tecnológica e a formação de capital. Como já indicamos, as duas teorias têm muitos pontos em comum: a) sua cláusula conseqüente é a mesma: o desenvolvimento econômico; b) os dois autores tentam generalizar seus resultados para qualquer sociedade; c) a cláusula antecedente das duas teorias apóia-se em fatôres sociopsicológicos; d) HAGEN e McClelland, em geral, consideram que só se atinge o desenvolvimento econômico através de um aumento de produção per capita. As principais diferenças entre ambos aparecem nos têrmos que compõem suas cláusulas antecedentes. MCClellaNd trabalha com práticas de educação infantil relacionadas com o nível de motivação para realizações enquanto HAGEN trabalha com o declínio no respeito pelo status como condição necessária para a emergência de personalidades inovadoras nas sociedades tradicionais. Em geral, HAGEN emprega a idéia de causalidade com maior frequiência que MCClELLAND. E também mais inclinado a falar de condições necessárias e suficientes.

Ao criticar a metodologia de HAGeN e McClelland não pretendíamos afirmar que suas teorias não são válidas. Em muitos casos tentamos simplesmente mostrar que tanto o delineamento da pesquisa quanto as técnicas empregadas não eram de molde a garantir as conclusões e as inferências lógicas. Em outros casos sugerimos que o modo de definir (ou de não definir) os conceitos implicados nas cláusulas consequientes tornaram muito inadequadas as generalizações a qualquer sociedade. No caso de HAGEN, especificamente, sugerimos que sua teoria deveria ser restringida às sociedades tradicionais onde mecanismos de contrôle que inibem a emergência de inovação em muitas áreas de cultura tornam-se disfuncionais. Em outras palavras, aceitamos que a idéia de privação relativa, implícita na concepção de insatisfação, de HAGEN, seja uma condição importante para a emergência de atitudes favoráveis para o desenvolvimento econômico e para a mudança social. Entretanto não aceitamos a idéia que a simples existência e a percepção da privação relativa seja uma condição suficiente para um take-off psicológico ou declínio no respeito pelo status e, conseqüentemente, para a emergência da personalidade 
inovadora. Dada uma estrutura social dominada por fortes mecanismos de contrôle social e não dispondo de canais completamente institucionalizados de expressão dos sentimentos, êstes serão realmente bloqueados. Numa palavra, os indivíduos defrontando separadamente os contrôles sociais institucionalizados são incapazes de provocar mudanças ou de transformar-se em personalidades inovadoras. Assim, os elementos estruturais deveriam integrar a teoria de HAGEN a fim de possibilitar a margem de variação dentro da qual o declínio no respeito pelo status possa manifestar-se. Este comentário pode aplicar-se a McClelland: a formação e a participação efetiva dos grandes realizadores no sistema, depende, em grande parte, de fatôres estruturais nem sempre considerados (aliás, quando alguns dêstes fatôres eram introduzidos em estudos parciais apresentados por MCClelland, a fôrça da motivação para realização como variável explanatória do desenvolvimento econômico via-se muito reduzida). Impõe-se ainda outro comentário geral sôbre os dois autores. Como observamos, as duas teorias estão centradas em características sociopsicológicas adquiridas durante a primeira socialização. Esta perspectiva parece muito estreita, além de ser um enfoque perigoso pois pode nos conduzir a um beco sem saída. Em outras palavras, se a motivação para realização ou a personalidade inovadora são qualidades formadas nos primeiros estágios do processo de socialização (independência, domínio de si, necessidades, etc.), como é possível pensar em mudança na fase adulta? Mais especificamente: como sabemos, os responsáveis pela ordem social existente e pelo estado atual de desenvolvimento econômico são os adultos. Então, como podem êles mudar as condições existentes ou mudar seus filhos, se a grande proporção (se não tôda) de criatividade e de realização foi formada durante sua infância? Numa palavra, HAGeN e McClelland parecem levarnos a um sistema fechado e morto, ao eliminar as possibilidades de mudança na personalidade, fora da primeira socialização.

\section{Bônus da UNESCO}

Facilidades especiais para importações, sem saída de divisas nacionais.

Livros, revistas, materiais científicos e audiovisuais são obtidos através dos bônus da UNESCO.

Os bônus são utilizados também para pagamentos de sociedades científicas e culturais, e de direitos autorais. Atendem-se pedidos de bônus por correspondência.

Informações: Praia de Botafogo, 186 - Caixa Postal 21.120

- Rio - GB - ZC-05 